\title{
Effects of water on breakdown characteristics of polyethylene composites
}

Article

Accepted Version

Creative Commons: Attribution-Noncommercial-No Derivative Works 4.0

Lau, K.Y., Zafrullah, S.N.R.M., Ismail, I.Z. and Ching, K. Y. (2018) Effects of water on breakdown characteristics of polyethylene composites. Journal of Electrostatics, 96. pp. 119-127. ISSN 0304-3886 doi:

https://doi.org/10.1016/j.elstat.2018.10.011 Available at https://centaur.reading.ac.uk/102029/

It is advisable to refer to the publisher's version if you intend to cite from the work. See Guidance on citing.

To link to this article DOI: http://dx.doi.org/10.1016/j.elstat.2018.10.011

Publisher: Elsevier

All outputs in CentAUR are protected by Intellectual Property Rights law, including copyright law. Copyright and IPR is retained by the creators or other copyright holders. Terms and conditions for use of this material are defined in the End User Agreement.

\section{www.reading.ac.uk/centaur}

\section{CentAUR}

Central Archive at the University of Reading 
Reading's research outputs online 


\title{
Effects of water on breakdown characteristics of polyethylene composites
}

\author{
K. Y. Lau ${ }^{1 *}$, S. N. R. M. Zafrullah ${ }^{1}$, I. Z. Ismail ${ }^{1}$, K. Y. Ching ${ }^{2}$ \\ ${ }^{1}$ Institute of High Voltage and High Current, School of Electrical Engineering, Universiti \\ Teknologi Malaysia, 81310 Johor Bahru, Malaysia \\ ${ }^{2}$ School of Foundation, University of Reading Malaysia, 79200 Iskandar Puteri, Malaysia \\ *Corresponding e-mail: kwanyiew@utm.my
}

\begin{abstract}
The current work investigated the effects of oxide- and nitride-based silicon nanoparticles on the water absorption and dielectric breakdown characteristics of low density polyethylene (LDPE). The results showed that hydrophobic LDPE, when added with silicon dioxide nanoparticles, became prone to water absorption. In contrast, LDPE, when added with silicon nitride nanoparticles, attracted much less water. These water absorption behaviors consequently affected the breakdown characteristics of the materials, where LDPE with silicon dioxide nanoparticles showed lower breakdown strength than LDPE with silicon nitride nanoparticles. These differences are discussed based on the surface chemistries of the nanoparticles.
\end{abstract}

Keywords: Breakdown; Water; Polyethylene; Silicon dioxide; Silicon nitride; Nanoparticles 


\subsection{Introduction}

Dielectric nanocomposites have been reported to possess favorable dielectric properties that the dielectric community has long been waiting for, such as improved partial discharge resistance, treeing propagation, space charge build-up and dielectric breakdown performance [1-10]. Due to the effect of nanostructuration, extensive particle surface areas are anticipated to be present around nanometer-sized fillers. Consequently, properly engineered surface states of nanoparticles, which commonly serve as the interfacial region between the nanoparticles and the polymer, would allow nanocomposites to function as unique high voltage electrical insulation materials [11-21].

Since the dielectric properties of nanocomposites are closely associated with the mechanisms at the nanoparticles' surface, several interfacial models have been suggested in attempts to explain the electrochemical features (i.e., chemical processes that result in changes in electrical properties) of nanocomposites. These include the diffuse electrical double layer model $[13,22,23]$, the multi-core model [14], the multi-region structure model [24] and the dual layer model [25]. Although each of the models has different viewpoints in relation to the interfacial region of nanocomposites, they exhibit a common element: the interfacial layer most adjacent to the nanoparticles is the key to controlling the dielectric behavior of nanocomposites. This highlights the importance of controlling the surface state of nanoparticles in engineering the dielectric properties of nanocomposites.

The mechanisms at the interfacial region of nanocomposites, largely affected by the nanoparticles' surface state are, however, far from being understood. Although the presence of the interfacial region has often been regarded as the main factor leading to the distinct dielectric properties of nanocomposites, it may also act as a preferred location for the aggregation of water molecules. For example, Zhang and Stevens [26] studied the dielectric behavior of nanoaluminafilled polyethylene upon water absorption and reported that dielectric loss peaks associated with 
absorbed water in unfilled and nanoalumina-filled polyethylene appeared at different frequencies and had different dynamics. Similar observations were reported for the case of nanoalumina-filled epoxy in comparison with unfilled epoxy. Zhang and Stevens [26] therefore suggested that water absorption behaviors in nanocomposites were different from unfilled polymers. Specifically, the interfacial region in nanocomposites, which was not found in unfilled materials, was likely to be the site for the aggregation of water molecules.

Zou et al. [27] also discovered that epoxy/silica nanocomposites absorbed significantly more water than unfilled epoxy when exposed to humid environmental conditions. The extra water was found to be located around the surface of silica nanoparticles, resulting in the presence of water shells surrounding the nanoparticles. Conversely, filler particles that have surfaces that were functionalized to be hydrophobic reduced considerably the amount of absorbed water in nanocomposites under the same conditions of humidity. Similar observations were reported by Huang et al. [28] for the case of polyethylene/silica nanocomposites.

Meanwhile, Fabiani et al. [29] investigated the effect of nanoparticle drying on water contents of nanocomposites and reported increased permittivity and loss in samples added with wet nanoparticles compared to samples added with dried nanoparticles. These adverse dielectric effects were thought to be more pronounced in nanocomposites containing high aspect ratio fillers than in nanocomposites containing low aspect ratio fillers. Therefore, the presence of the nanoparticle/polymer interphase may negatively affect the overall dielectric performance of nanocomposites.

The recent work of Lau et al. [30, 31] demonstrated that polyethylene/silica nanocomposites absorbed significantly more water than unfilled polyethylene. Consequently, the permittivity and loss tangent of the nanocomposites increased with increasing duration of water immersion. Although the addition of nanosilica to polyethylene resulted in significant water uptake 
(presumably due to the presence of the interphase) compared to unfilled polyethylene, surface functionalization of nanosilica using trimethoxy(propyl)silane coupling agent was found to improve matters, with less water uptake, lower permittivity and lower loss tangent. Similar findings were reported by Hosier et al. [32] with the use of silicon nitride nanoparticles in place of functionalized silica nanoparticles. These findings lead to the suggestion that the surface states (or more precisely, the surface chemistries) of nanoparticles are vital in establishing the interfacial region of nanocomposites, which subsequently determine the materials' dielectric behaviors.

To date, published literature on the effect of water absorption in relation to the breakdown characteristics of polyethylene nanocomposites is relatively scarce. Although polyethylene itself is hydrophobic, the addition of nanoparticles could alter the water absorption behavior of the resulting nanocomposites due to the presence of the interfacial region between the nanoparticles and polymer that could act as a preferred site for the aggregation of water molecules [33]. Consequently, the presence of water can have detrimental effects on the otherwise improved electrical properties of dielectric materials [34-37]. In the current work, the tendency for hydrophobic low density polyethylene (LDPE) to absorb water upon nanoparticle addition was investigated. Two types of nanoparticles with different surface chemistries, i.e., silicon dioxide $\left(\mathrm{SiO}_{2}\right)$ and silicon nitride $\left(\mathrm{Si}_{3} \mathrm{~N}_{4}\right)$, were added respectively to LDPE to explore the interfacial mechanisms with regard to water absorption and breakdown characteristics of the resulting nanocomposites.

\subsection{Experimental}

\subsection{Materials and sample preparation}

The polymer used in the experimental work was LDPE (Titanlene LDF200YZ, (Lotte Chemical Titan). The nanoparticles used were silicon dioxide $\left(\mathrm{SiO}_{2}\right)$ nanopowder and silicon nitride $\left(\mathrm{Si}_{3} \mathrm{~N}_{4}\right)$ nanopowder, obtained from NanoAmor. The $\mathrm{Si}_{3} \mathrm{~N}_{4}$ nanoparticles had a 
manufacturer-quoted average particle size of $15-30 \mathrm{~nm}$. For the $\mathrm{SiO}_{2}$ nanoparticles, two manufacturer-quoted average particle sizes were considered, i.e., $20 \mathrm{~nm}$ and $80 \mathrm{~nm}$ - these $\mathrm{SiO}_{2}$ nanoparticles were referred to as $20 \mathrm{SiO}_{2}$ and $80 \mathrm{SiO}_{2}$, respectively, hereafter. Figure 1 illustrates that $\mathrm{SiO}_{2}$ nanoparticles typically contains $\mathrm{Si}-\mathrm{O}-\mathrm{Si}$ bonds [38-41] while $\mathrm{Si}_{3} \mathrm{~N}_{4}$ nanoparticles typically contains Si-N-Si bonds [42-44]; this will be further discussed later.

(a)

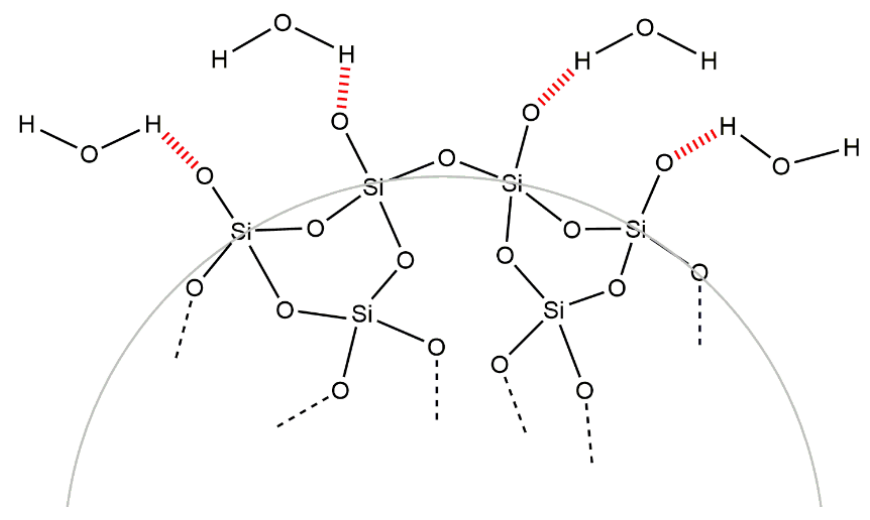

(b)

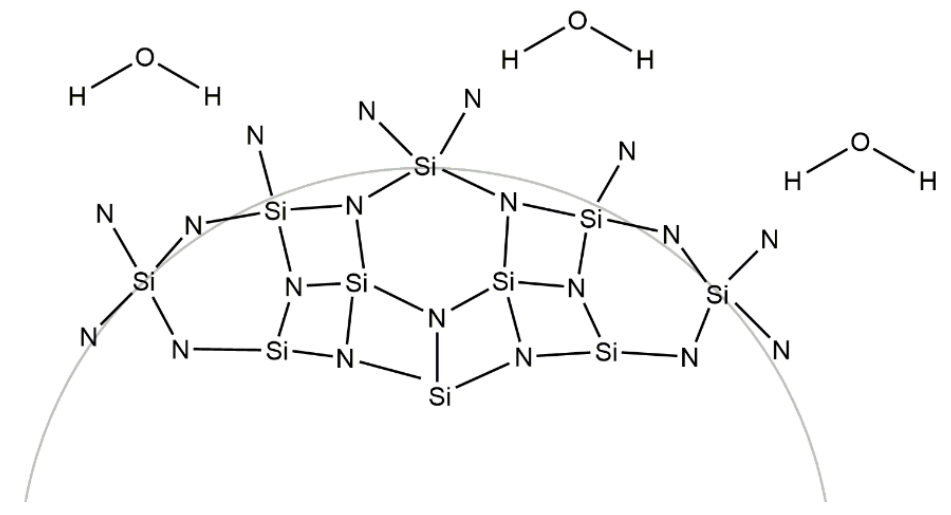

Figure 1. Surface chemistries of (a) $\mathrm{SiO}_{2}$, (b) $\mathrm{Si}_{3} \mathrm{~N}_{4}$.

Nanocomposite samples were prepared using a mechanical mixing method. The desired amount of $20 \mathrm{SiO}_{2}, 80 \mathrm{SiO}_{2}$ or $\mathrm{Si}_{3} \mathrm{~N}_{4}$ nanoparticles was mixed with LDPE in a laboratory two-roll mill at a temperature of $140{ }^{\circ} \mathrm{C}$ for $15 \mathrm{~min}$. Samples for water immersion tests and breakdown measurements were then prepared using a hydraulic laboratory press at a temperature of $160{ }^{\circ} \mathrm{C}$ and a load of 3 ton. The thickness of the prepared samples was $100 \mu \mathrm{m}$. 


\subsection{Characterization}

The prepared samples were immersed in distilled water and, at different time periods, were removed and dried with tissues, followed by sample weighing and DC breakdown testing. The sample weights (typically $0.5 \mathrm{~g}$ ) were monitored using a 4-digit analytical balance (OHAUS PA214C); repeated measurements indicate an uncertainty in all measurements of about $\pm 0.04 \%$. The percentage increase in mass for each sample was calculated using the following equation:

$$
\% \text { Mass }=\left|\frac{M_{w}-M_{a}}{M_{a}}\right| \times 100 \%
$$

where $M_{w}$ is the weight of a water absorbed sample while $M_{a}$ is the weight of the sample prior to water immersion.

DC breakdown testing was conducted by placing a test sample between two opposing 6.35 mm diameter steel ball-bearing electrodes immersed in Hyrax Hypertrans transformer oil to prevent surface flashover. A DC voltage with a step voltage of $2 \mathrm{kV}$ every $20 \mathrm{~s}$ was applied until the sample experienced breakdown. Fifteen breakdown tests were performed on each type of material. The voltage obtained from each measurement was divided by the sample thickness at the breakdown point in order to obtain the breakdown field. The resulting dielectric breakdown data were statistically analyzed assuming two-parameter Weibull statistics [45, 46].

\subsection{Results}

\subsection{Water uptake characteristics}

\subsubsection{Changes in absorbed water over water immersion period}

Figure 2 shows the water uptake characteristics of LDPE with $20 \mathrm{SiO}_{2}, 80 \mathrm{SiO}_{2}$ and $\mathrm{Si}_{3} \mathrm{~N}_{4}$. For referencing purposes, unfilled LDPE showed negligible water absorption effects. However, 
adding $20 \mathrm{SiO}_{2}$ to $\mathrm{LDPE}$ resulted in an increase in the material's mass upon water immersion. After three days of water immersion, the mass of LDPE with $3 \mathrm{wt} \%$ of $20 \mathrm{SiO}_{2}$ increased as much as $0.93 \%$. The mass of the sample increased to $1.73 \%$ after immersing in water for 15 days. By adding $10 \mathrm{wt} \%$ of $20 \mathrm{SiO}_{2}$ to LDPE, the water absorption effects became more apparent than the $3 \mathrm{wt} \%$ equivalent counterparts - the water uptake percentage increased to $1.61 \%$ and $2.01 \%$ after three and fifteen days of water immersion, respectively. The addition of $80 \mathrm{SiO}_{2}$ to LDPE also resulted in an increase in the material's mass upon water immersion. Nevertheless, the water uptake characteristics of $\mathrm{LDPE}$ with $80 \mathrm{SiO}_{2}$ and $\mathrm{LDPE}$ with $20 \mathrm{SiO}_{2}$ were similar.

Although the addition of $\mathrm{Si}_{3} \mathrm{~N}_{4}$ to LDPE resulted in an increase in the material's mass upon water immersion, the increase is much less compared to LDPE with $20 \mathrm{SiO}_{2}$ or $80 \mathrm{SiO}_{2}$. After three days of water immersion, the mass increase for LDPE with $1 \mathrm{wt} \%$ and $3 \mathrm{wt} \%$ of $\mathrm{Si}_{3} \mathrm{~N}_{4}$ was negligibly small ( 0.08\%). Generally, the water absorption effects of LDPE with $\mathrm{Si}_{3} \mathrm{~N}_{4}$ became more apparent with an increasing amount of $\mathrm{Si}_{3} \mathrm{~N}_{4}$. After 20 days of water immersion, LDPE with $5 \mathrm{wt} \%$ of $\mathrm{Si}_{3} \mathrm{~N}_{4}$ showed an increase of $0.68 \%$ water absorption, much less than the water absorption effects of $\mathrm{LDPE}$ with $20 \mathrm{SiO}_{2}$ and $80 \mathrm{SiO}_{2}$. 


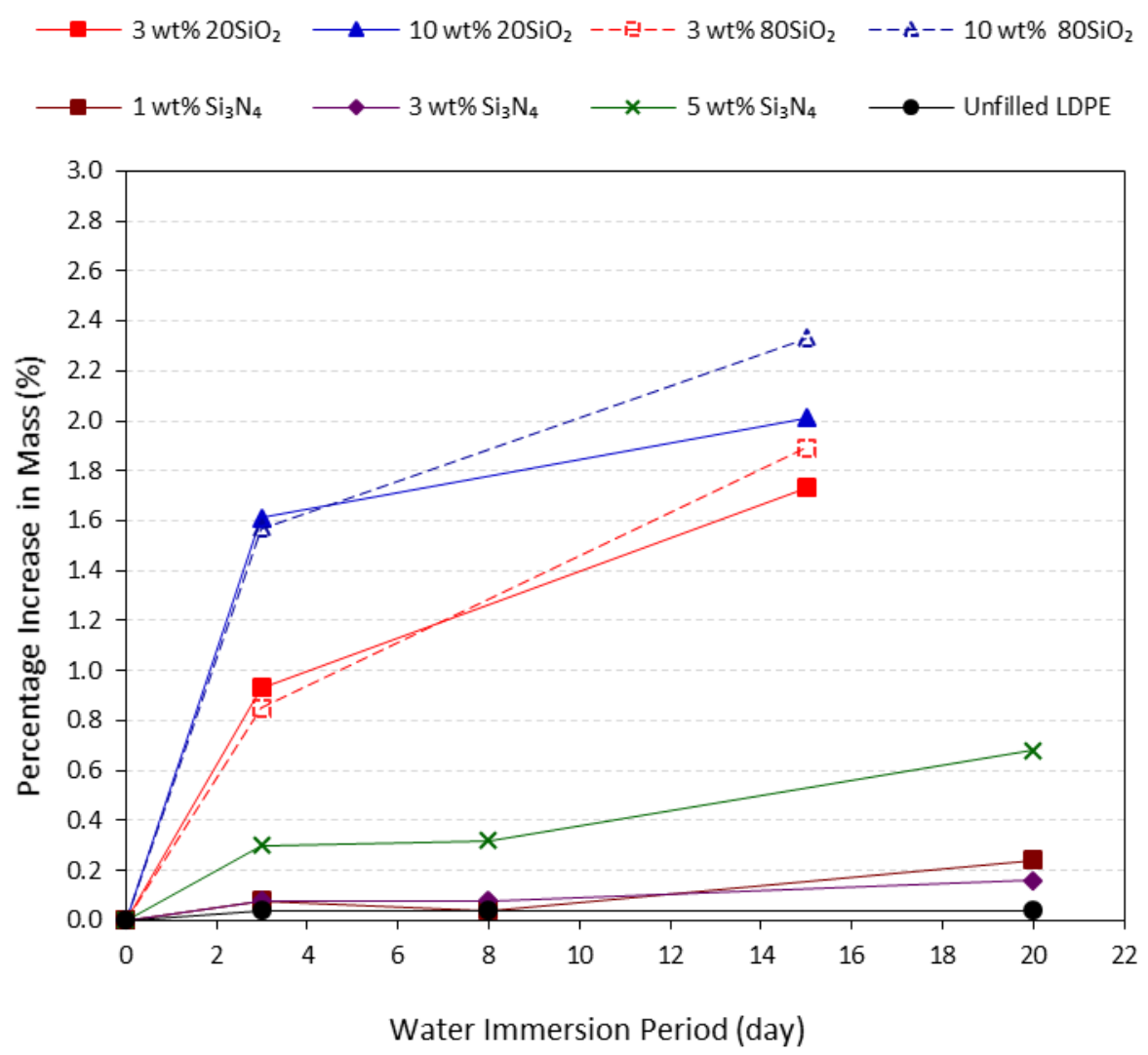

Figure 2. Percentage increase in mass for $\mathrm{LDPE}$ with $20 \mathrm{SiO}_{2}, 80 \mathrm{SiO}_{2}$ and $\mathrm{Si}_{3} \mathrm{~N}_{4}$, with unfilled $\mathrm{LDPE}$ as a reference

\subsubsection{Changes in absorbed water over nanoparticle loading levels}

Figure 3 shows the plot of the mass increase (or water absorption) for $\mathrm{LDPE}$ with $20 \mathrm{SiO}_{2}$, $80 \mathrm{SiO}_{2}$ and $\mathrm{Si}_{3} \mathrm{~N}_{4}$ over different nanoparticle loading levels after immersing in water for different time periods. Apparently, the water uptake capability of LDPE with $\mathrm{Si}_{3} \mathrm{~N}_{4}$ was different from that of $\mathrm{LDPE}$ with $20 \mathrm{SiO}_{2}$ and $80 \mathrm{SiO}_{2}$. The mass of LDPE with $\mathrm{Si}_{3} \mathrm{~N}_{4}$ did not increase much for the amount of nanoparticles up to $3 \mathrm{wt} \%$. Meanwhile, the mass of $\mathrm{LDPE}$ with $20 \mathrm{SiO}_{2}$ and $80 \mathrm{SiO}_{2}$ increased up to $1 \%$ for nanoparticle loading level of $3 \mathrm{wt} \%$. Nevertheless, the mass increase became less steep between $3 \mathrm{wt} \%$ and $10 \mathrm{wt} \%$ of nanoparticle loading level. Similar trends of water 
absorption over nanoparticle loading levels were observed after the samples were immersed in water for fifteen or twenty days.

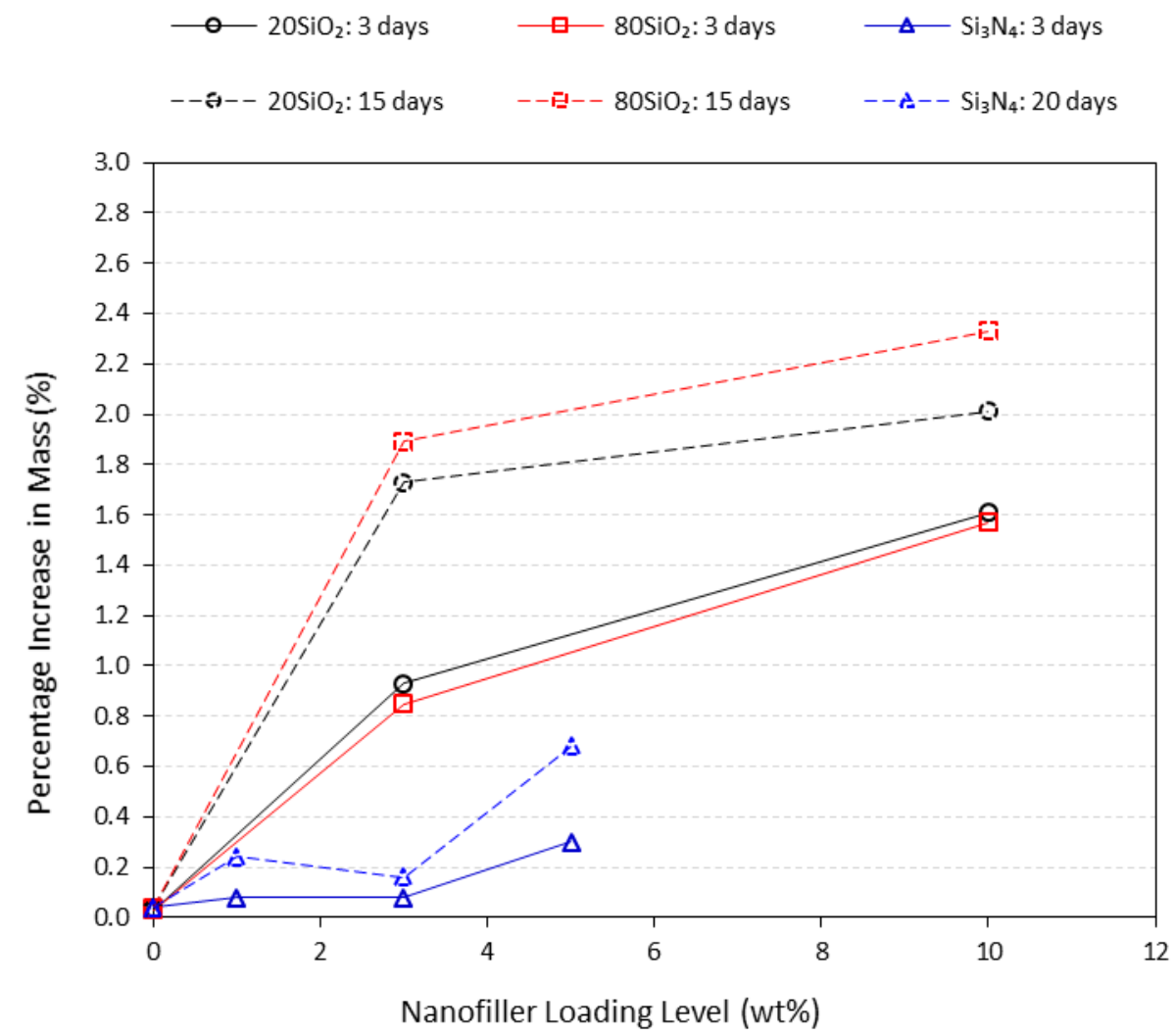

Figure 3. Percentage increase in mass for $\mathrm{LDPE}$ with $20 \mathrm{SiO}_{2}, 80 \mathrm{SiO}_{2}$ and $\mathrm{Si}_{3} \mathrm{~N}_{4}$ over different nanoparticle loading levels for different water immersion periods

\subsection{Breakdown characteristics}

\subsubsection{Breakdown strength of unfilled LDPE}

Figure 4a shows the breakdown strength of unfilled LDPE upon water immersion for 0,3 and 15 days (the Weibull parameters are shown in Table 1). Considering the uncertainties in Weibull analysis, the breakdown strength of unfilled LDPE was not affected upon water immersion. The unaltered breakdown strength of unfilled LDPE was further confirmed by another batch of similar LDPE sample immersed in water for 0, 3, 8 and 20 days (see Figure 4b). 
(a)

- Unfilled LDPE: 0 day

$\triangle$ Unfilled LDPE: 15 days

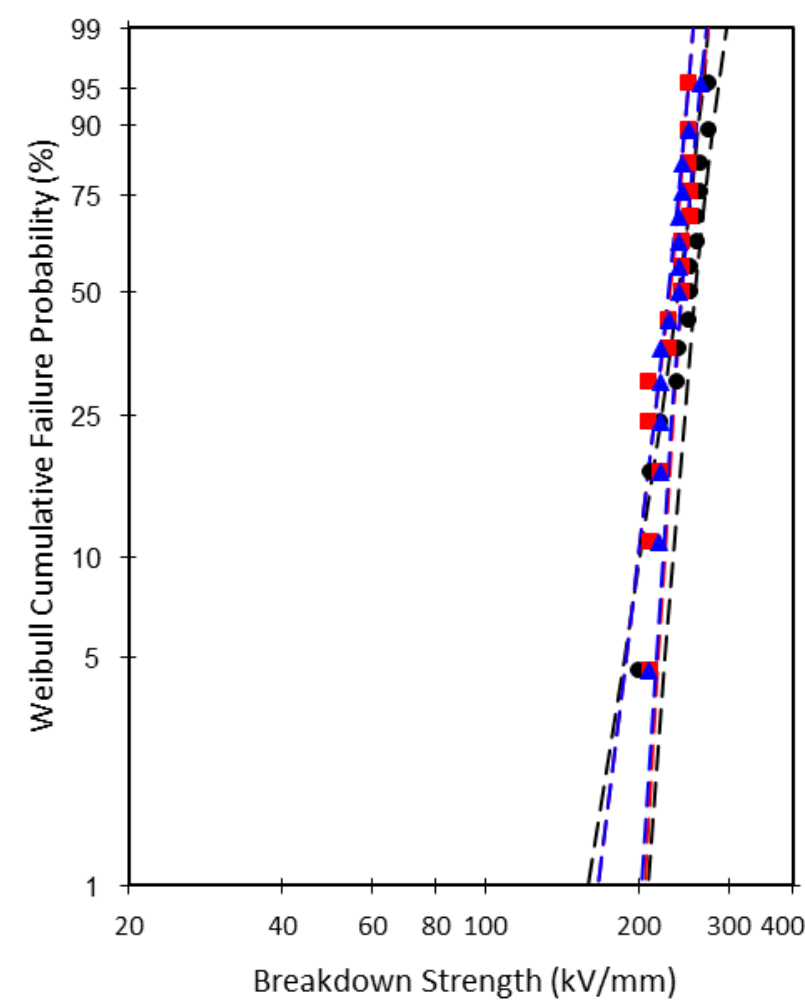

(b)

- Unfilled LDPE: 0 day

$\triangle$ Unfilled LDPE: 8 days

- Unfilled LDPE: 3 days

- Unfilled PE: 20 days

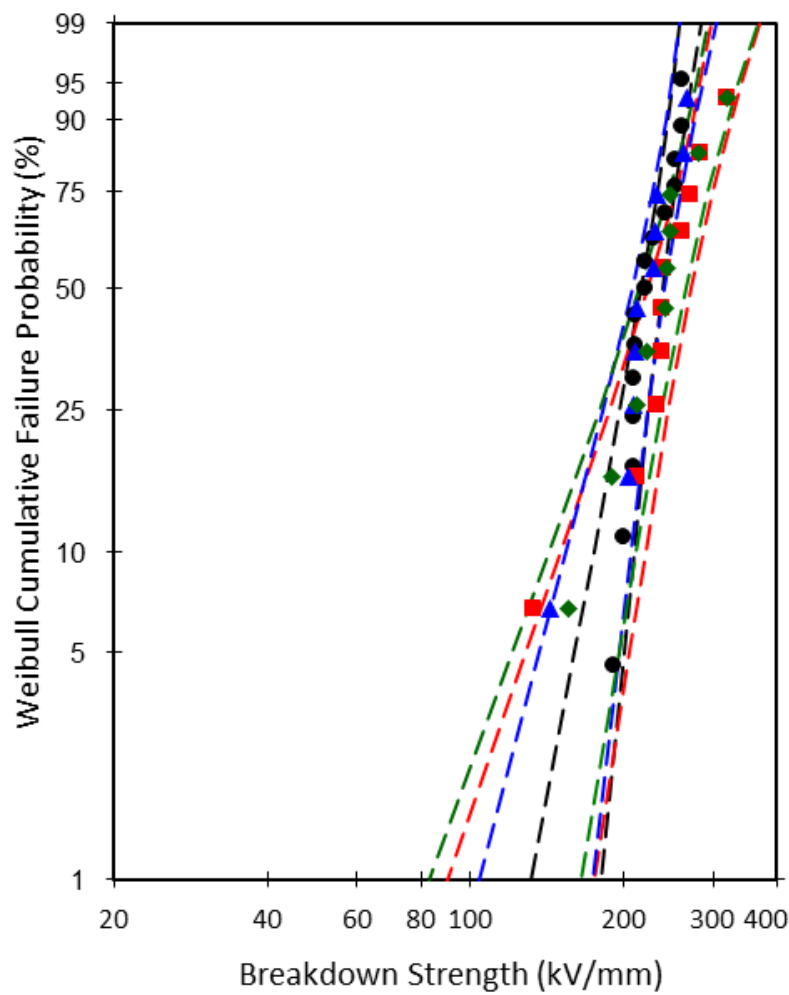

Figure 4. Breakdown strength of (a) unfilled LDPE samples upon water immersion for 0, 3 and 5 days, (b) another batch of similar LDPE samples upon water immersion for 0, 3, 8 and 20 days

Table 1. Weibull parameters for unfilled LDPE upon different water immersion periods

\begin{tabular}{lcc}
\hline Sample & $\boldsymbol{\alpha}(\mathbf{k V} / \mathbf{m m})$ & $\boldsymbol{\beta}$ \\
\hline Unfilled LDPE: 0 day & $254 \pm 9$ & $14 \pm 5$ \\
Unfilled LDPE: 0 day & $235 \pm 10$ & $11 \pm 4$ \\
Unfilled LDPE: 3 days & $241 \pm 6$ & $18 \pm 7$ \\
Unfilled LDPE: 3 days & $261 \pm 23$ & $6 \pm 3$ \\
Unfilled LDPE: 8 days & $234 \pm 16$ & $8 \pm 5$ \\
Unfilled LDPE: 15 days & $240 \pm 6$ & $17 \pm 6$ \\
Unfilled LDPE: 20 days & $254 \pm 25$ & $6 \pm 3$ \\
\hline
\end{tabular}

\subsubsection{Breakdown strength of $\mathrm{LDPE}$ with $20 \mathrm{SiO}_{2}$}

Figure 5a shows the breakdown strength of LDPE with $3 \mathrm{wt} \%$ of $20 \mathrm{SiO}_{2}$ (the breakdown strength of unfilled LDPE from Figure $4 \mathrm{a}$ are re-shown as grey colored background). The 
breakdown strength of LDPE with $3 \mathrm{wt} \%$ of $20 \mathrm{SiO}_{2}$ was not as high as that of unfilled LDPE. In addition, the breakdown strength of LDPE with $3 \mathrm{wt} \%$ of $20 \mathrm{SiO}_{2}$ reduced with increasing water immersion periods. A similar breakdown trend was also observed for LDPE with $10 \mathrm{wt} \%$ of $20 \mathrm{SiO}_{2}$ (see Figure 5b; the breakdown strength of unfilled LDPE from Figure 4a and LDPE with 3 wt\% of $20 \mathrm{SiO}_{2}$ from Figure 5a are re-shown as grey colored background). Furthermore, the reduction of breakdown strength was more apparent for LDPE with $10 \mathrm{wt} \%$ of $20 \mathrm{SiO}_{2}$ compared to LDPE with $3 \mathrm{wt} \%$ of $20 \mathrm{SiO}_{2}$. The Weibull parameters for $\mathrm{LDPE}$ with $20 \mathrm{SiO}_{2}$ are shown in Table 2.

(a)

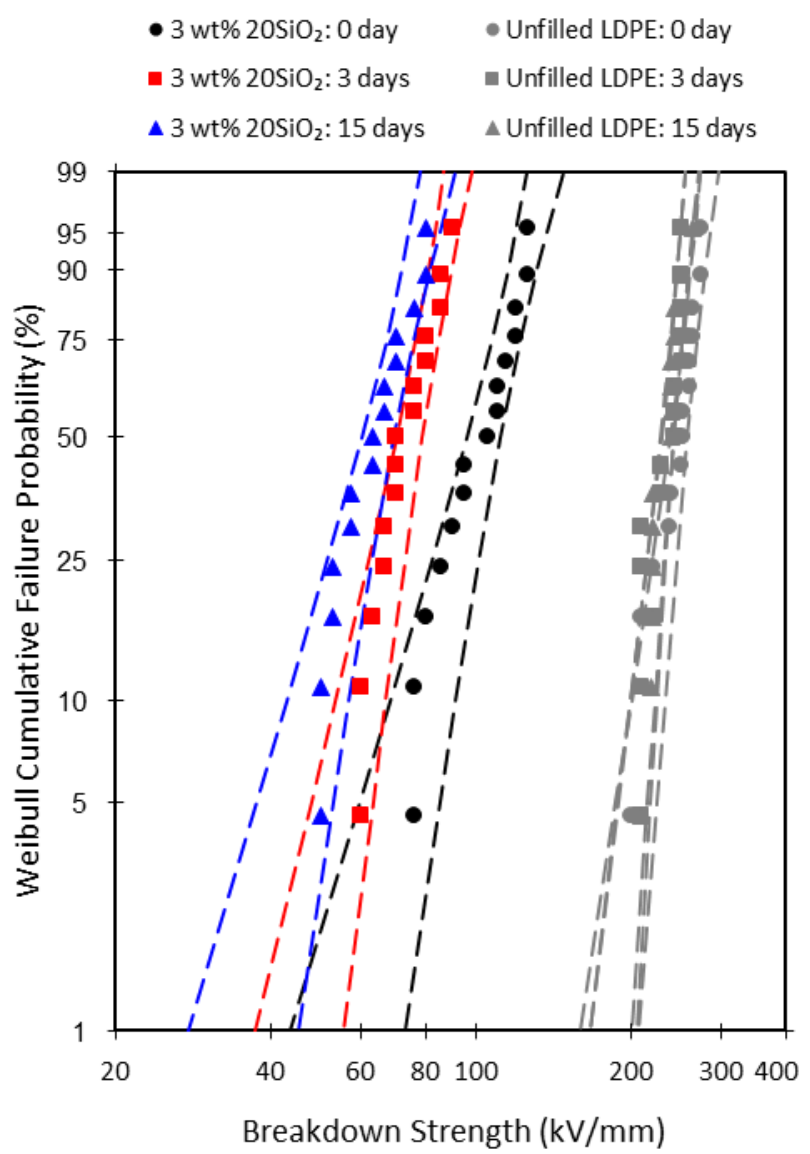

(b)

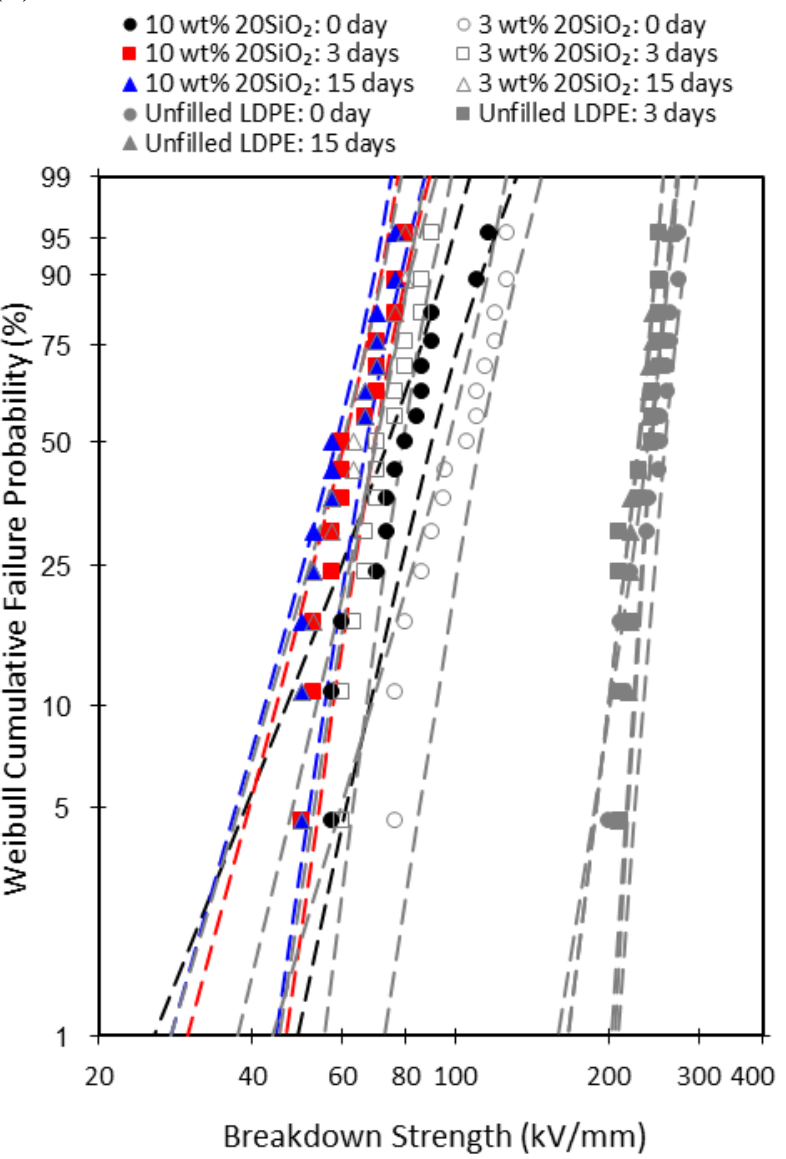

Figure 5. Breakdown strength of LDPE with (a) $3 \mathrm{wt} \%$ of $20 \mathrm{SiO}_{2}$ upon water immersion for 0,3 and 15 days (unfilled LDPE from Figure $4 \mathrm{a}$ are re-shown as grey colored background), (b) $10 \mathrm{wt} \%$ of $20 \mathrm{SiO}_{2}$ upon water immersion for 0, 3 and 15 days (unfilled LDPE from Figure 4a and LDPE with $3 \mathrm{wt} \%$ of $20 \mathrm{~nm} \mathrm{SiO}_{2}$ from Figure 5a are re-shown as grey colored background) 
Table 2. Weibull parameters for LDPE with $3 \mathrm{wt} \%$ and $10 \mathrm{wt} \%$ of $20 \mathrm{SiO}_{2}$ upon water immersion for 0,3 and 15 days

\begin{tabular}{|c|c|c|}
\hline Sample & $\alpha(\mathrm{kV} / \mathbf{m m})$ & $\beta$ \\
\hline $3 \mathrm{wt} \% 20 \mathrm{SiO}_{2}: 0$ day & $109 \pm 8$ & $7 \pm 3$ \\
\hline $3 \mathrm{wt} \% 20 \mathrm{SiO}_{2}: 3$ days & $77 \pm 5$ & $9 \pm 3$ \\
\hline $3 \mathrm{wt} \% 20 \mathrm{SiO}_{2}: 15$ days & $68 \pm 5$ & $7 \pm 3$ \\
\hline $10 \mathrm{wt} \% 20 \mathrm{SiO}_{2}: 0$ day & $87 \pm 9$ & $5 \pm 2$ \\
\hline $10 \mathrm{wt} \% 20 \mathrm{SiO}_{2}: 3$ days & $68 \pm 4$ & $8 \pm 3$ \\
\hline $10 \mathrm{wt} \% 20 \mathrm{SiO}_{2}: 15$ days & $66 \pm 4$ & $7 \pm 3$ \\
\hline
\end{tabular}

\subsubsection{Breakdown strength of $\mathrm{LDPE}$ with $\mathrm{80SiO}_{2}$}

Figure 6 a shows the breakdown strength of LDPE with 3 wt $\%$ of $80 \mathrm{SiO}_{2}$. Again, the breakdown strength of the samples reduced with increasing water immersion periods. A similar trend was also observed for LDPE with $10 \mathrm{wt} \%$ of $80 \mathrm{SiO}_{2}$ (see Figure 6b). Again, the reduction of breakdown strength was more apparent for LDPE with $10 \mathrm{wt} \%$ of $80 \mathrm{SiO}_{2}$ compared to LDPE with $3 \mathrm{wt} \%$ of $80 \mathrm{SiO}_{2}$. The Weibull parameters for $\mathrm{LDPE}$ with $80 \mathrm{SiO}_{2}$ are shown in Table 3 . 


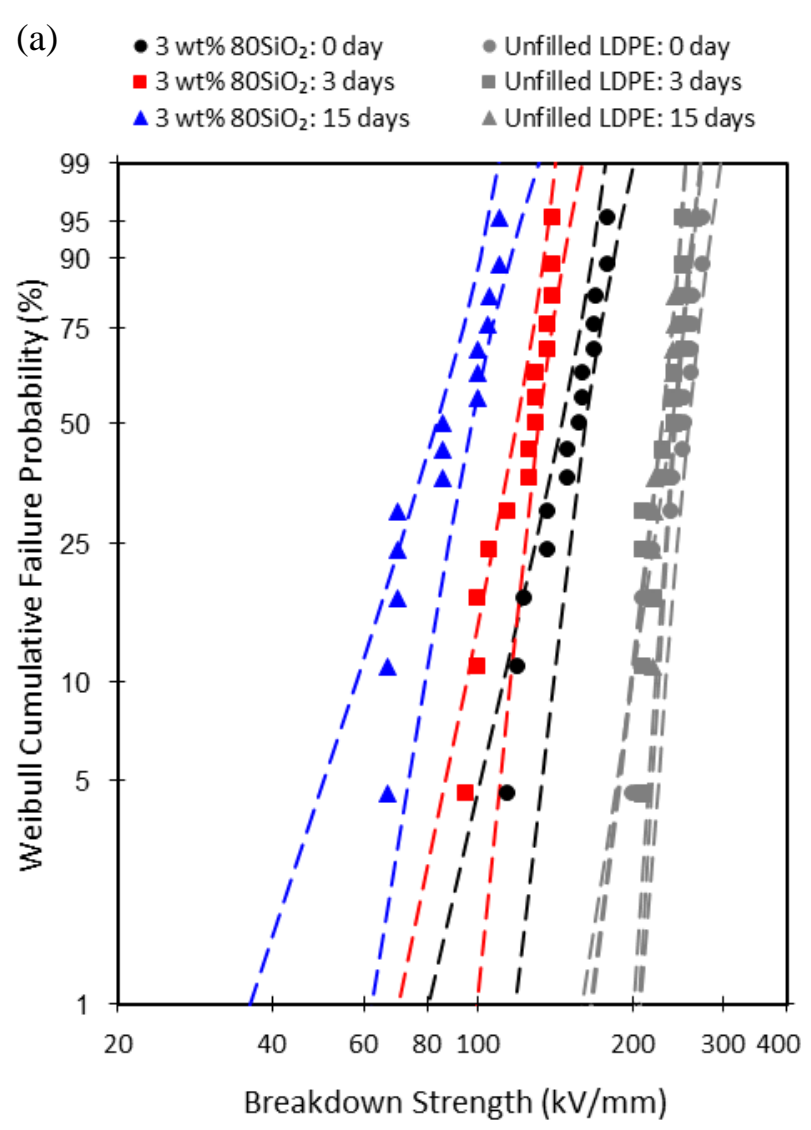
(b) $10 w t \% 80 \mathrm{SiO}_{2}$ : 0 day
- $10 \mathrm{wt} \% 80 \mathrm{SiO}_{2}: 3$ days
^ 10 wt $\% 80 \mathrm{SiO}_{2}$ : 15 days
- Unfilled LDPE: 0 day

- 3 wt $\% 80 \mathrm{SiO}_{2}$ : 0 day

$\square 3 \mathrm{wt} \% 80 \mathrm{SiO}_{2}$ : 3 days

$\triangle 3 \mathrm{wt} \% 80 \mathrm{SiO}_{2}: 15$ days

- Unfilled LDPE: 3 days

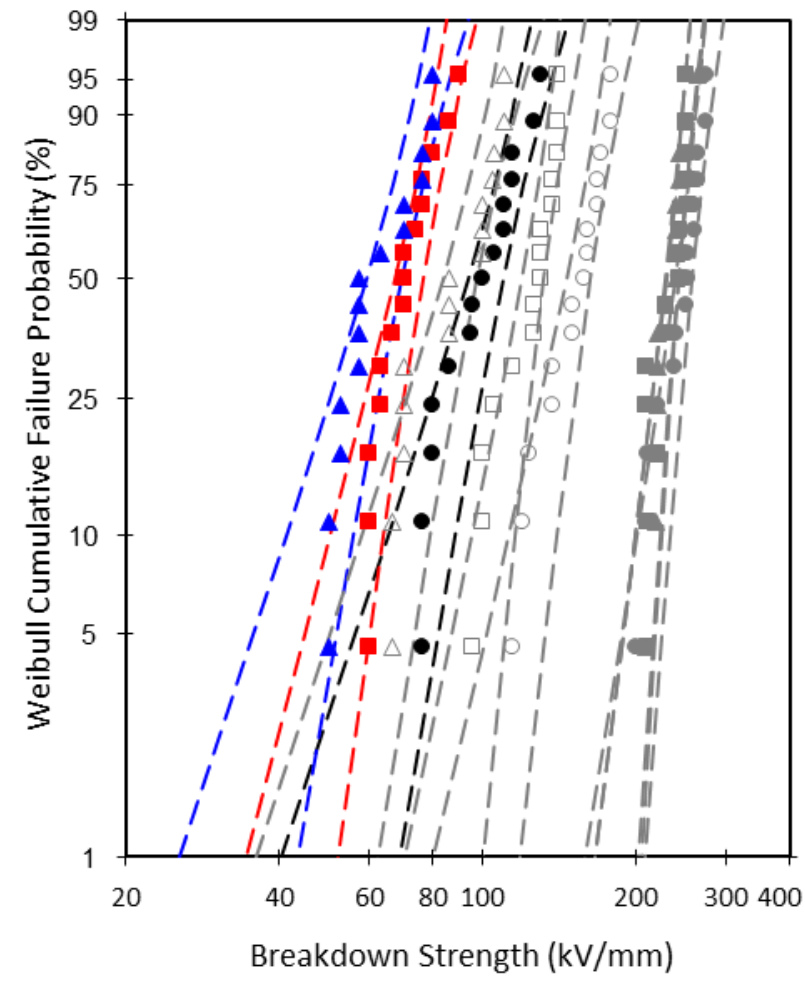

Figure 6. Breakdown strength of LDPE with (a) $3 \mathrm{wt} \%$ of $80 \mathrm{SiO}_{2}$ upon water immersion for 0,3 and 15 days (unfilled LDPE from Figure 4a are re-shown as grey colored background), (b) $10 \mathrm{wt} \%$ of $80 \mathrm{SiO}_{2}$ upon water immersion for 0, 3 and 15 days (unfilled LDPE from Figure 4a and LDPE with $3 \mathrm{wt} \%$ of $80 \mathrm{~nm} \mathrm{SiO}_{2}$ from Figure 6a are re-shown as grey colored background)

Table 3. Weibull parameters for LDPE with $3 \mathrm{wt} \%$ and $10 \mathrm{wt} \%$ of $80 \mathrm{SiO}_{2}$ upon water immersion for 0,3 and 15 days

\begin{tabular}{|c|c|c|}
\hline Sample & $\alpha(\mathrm{kV} / \mathrm{mm})$ & $\beta$ \\
\hline $3 \mathrm{wt} \% 80 \mathrm{~nm} \mathrm{SiO} 2: 0$ day & $160 \pm 8$ & $9 \pm 4$ \\
\hline $3 \mathrm{wt} \% 80 \mathrm{~nm} \mathrm{SiO} 2: 3$ days & $130 \pm 6$ & $11 \pm 4$ \\
\hline $3 \mathrm{wt} \% 80 \mathrm{~nm} \mathrm{SiO} 2: 15$ days & $95 \pm 7$ & $7 \pm 2$ \\
\hline $10 \mathrm{wt} \% 80 \mathrm{~nm} \mathrm{SiO}{ }_{2}: 0$ day & $107 \pm 8$ & $6 \pm 3$ \\
\hline $10 \mathrm{wt} \% 80 \mathrm{~nm} \mathrm{SiO}_{2}: 3$ days & $75 \pm 4$ & $8 \pm 3$ \\
\hline $10 \mathrm{wt} \% 80 \mathrm{~nm} \mathrm{SiO}_{2}: 15$ days & $68 \pm 3$ & $6 \pm 3$ \\
\hline
\end{tabular}

\subsubsection{Breakdown strength of LDPE with $\mathrm{Si}_{3} \mathrm{~N}_{4}$}

Figure 7 a shows the breakdown characteristics of LDPE with 1 wt $\%$ of $\mathrm{Si}_{3} \mathrm{~N}_{4}$. Before subjected to water immersion, the breakdown strength of LDPE with 1 wt\% of $\mathrm{Si}_{3} \mathrm{~N}_{4}$ was 244 
$\mathrm{kV} / \mathrm{mm}$, similar to the breakdown strength of unfilled LDPE. After immersing in water for 3 days, the breakdown strength of LDPE with $1 \mathrm{wt} \%$ of $\mathrm{Si}_{3} \mathrm{~N}_{4}$ reduced drastically to $130 \mathrm{kV} / \mathrm{mm}$. Further reductions of the breakdown strength were observed after LDPE with 1 wt $\%$ of $\mathrm{Si}_{3} \mathrm{~N}_{4}$ was immersed in water for 8 and 20 days.

Figure $7 \mathrm{~b}$ shows that the breakdown trend for LDPE with $3 \mathrm{wt} \%$ of $\mathrm{Si}_{3} \mathrm{~N}_{4}$ is similar to that of LDPE with $1 \mathrm{wt} \%$ of $\mathrm{Si}_{3} \mathrm{~N}_{4}$. However, the addition of $5 \mathrm{wt} \%$ of $\mathrm{Si}_{3} \mathrm{~N}_{4}$ to LDPE significantly reduced the breakdown strength of the material to $180 \mathrm{kV} / \mathrm{mm}$ (see Figure 7c). Again, the breakdown strength of the samples reduced with increasing water immersion periods. The Weibull parameters for LDPE with $\mathrm{Si}_{3} \mathrm{~N}_{4}$ are shown in Table 4. 
(a)

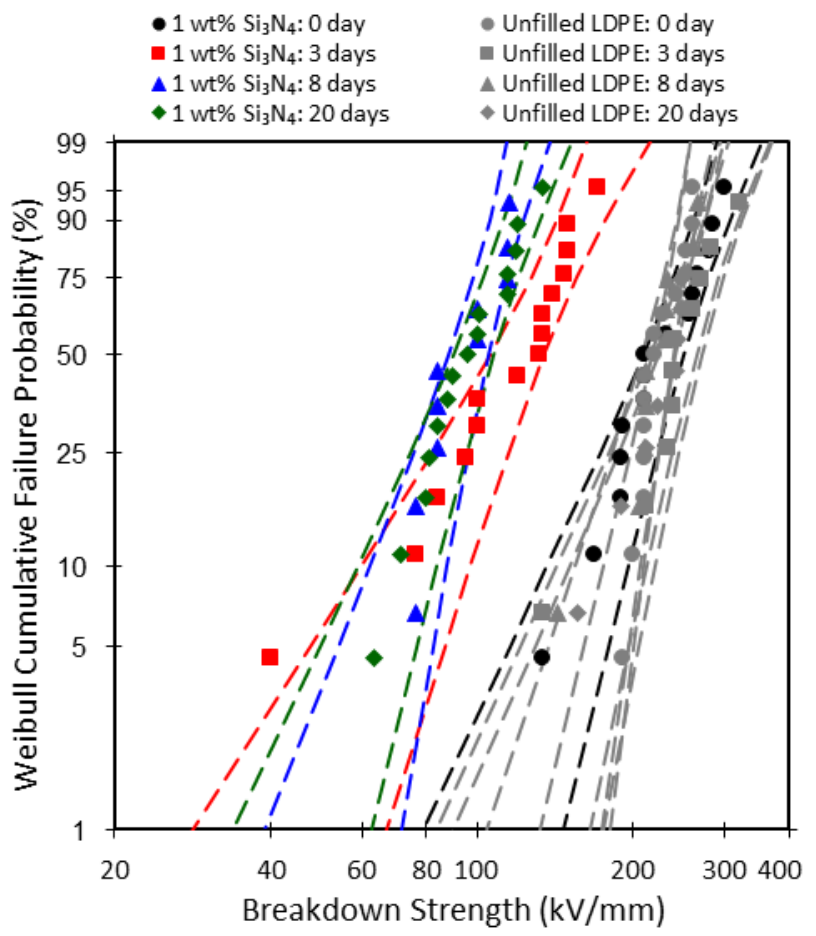

(b)

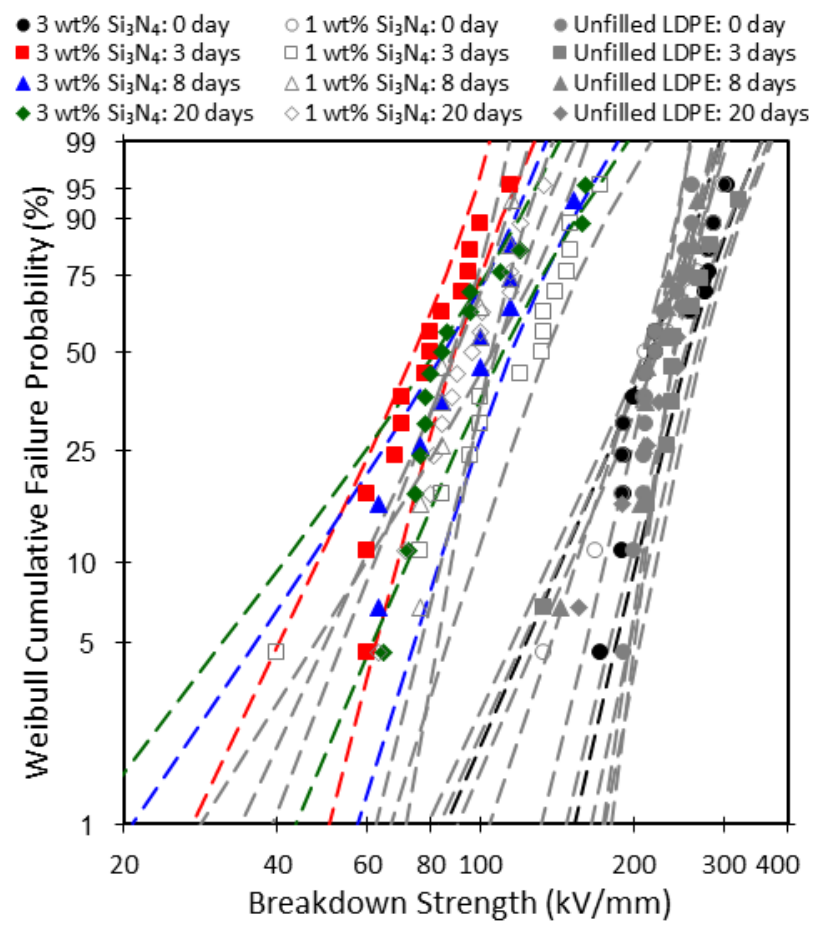

(c)
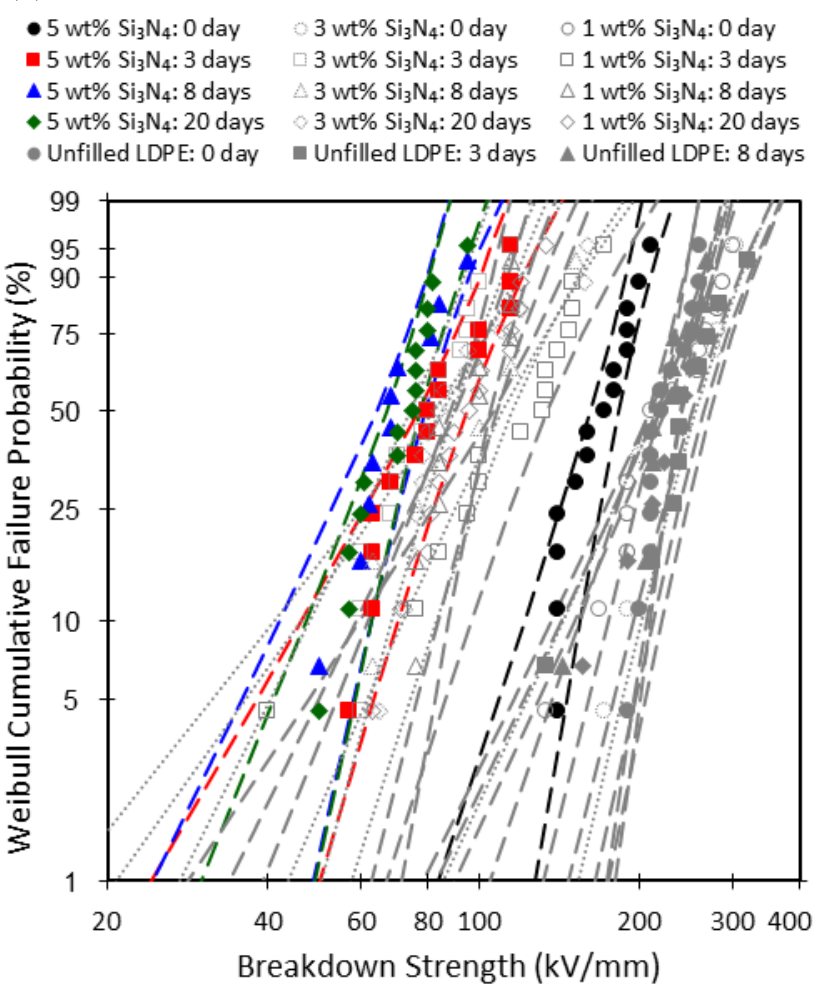

Figure 7. Breakdown strength of LDPE with (a) $1 \mathrm{wt} \%$ of $\mathrm{Si}_{3} \mathrm{~N}_{4}$ upon water immersion for $0,3,8$ and 20 days (unfilled LDPE from Figure 4a are re-shown as grey colored background), (b) $3 \mathrm{wt} \%$ of $\mathrm{Si}_{3} \mathrm{~N}_{4}$ upon water immersion for 0, 3, 8 and 20 days (unfilled LDPE from Figure 4a and LDPE with 3 wt $\%$ of $\mathrm{Si}_{3} \mathrm{~N}_{4}$ from Figure $7 \mathrm{a}$ are re-shown as grey colored background), (c) $5 \mathrm{wt} \%$ of $\mathrm{Si}_{3} \mathrm{~N}_{4}$ upon water immersion for $0,3,8$ and 20 days (unfilled LDPE from Figure 4a, LDPE with $1 \mathrm{wt} \%$ of $\mathrm{Si}_{3} \mathrm{~N}_{4}$ from Figure $7 \mathrm{a}$ and LDPE with $3 \mathrm{wt} \%$ of $\mathrm{Si}_{3} \mathrm{~N}_{4}$ from Figure $7 \mathrm{~b}$ are re-shown as grey colored background) 
Table 4. Weibull parameters for LDPE with $1 \mathrm{wt} \%, 3 \mathrm{wt} \%$ and $5 \mathrm{wt} \%$ of $\mathrm{Si}_{3} \mathrm{~N}_{4}$ upon water immersion for $0,3,8$ and 20 days

\begin{tabular}{lcc}
\hline Sample & $\boldsymbol{\alpha}(\mathbf{k V} / \mathbf{m m})$ & $\boldsymbol{\beta}$ \\
\hline $1 \mathrm{wt} \% \mathrm{Si}_{3} \mathrm{~N}_{4}: 0$ day & $244 \pm 20$ & $6 \pm 2$ \\
$1 \mathrm{wt} \% \mathrm{Si}_{3} \mathrm{~N}_{4}: 3$ days & $130 \pm 15$ & $4 \pm 2$ \\
$1 \mathrm{wt} \% \mathrm{Si}_{3} \mathrm{~N}_{4}: 8$ days & $101 \pm 9$ & $7 \pm 4$ \\
$1 \mathrm{wt} \% \mathrm{Si}_{3} \mathrm{~N}_{4}: 20$ days & $105 \pm 9$ & $6 \pm 2$ \\
$3 \mathrm{wt} \% \mathrm{Si}_{3} \mathrm{~N}_{4}: 0$ day & $249 \pm 20$ & $6 \pm 2$ \\
$3 \mathrm{wt} \% \mathrm{Si}_{3} \mathrm{~N}_{4}: 3$ days & $87 \pm 8$ & $5 \pm 2$ \\
$3 \mathrm{wt} \% \mathrm{Si}_{3} \mathrm{~N}_{4}: 8$ days & $108 \pm 15$ & $4 \pm 4$ \\
$3 \mathrm{wt} \% \mathrm{Si}_{3} \mathrm{~N}_{4}: 20$ days & $106 \pm 15$ & $3 \pm 2$ \\
$5 \mathrm{wt} \% \mathrm{Si}_{3} \mathrm{~N}_{4}: 0$ day & $180 \pm 10$ & $8 \pm 4$ \\
$5 \mathrm{wt} \% \mathrm{Si}_{3} \mathrm{~N}_{4}: 3$ days & $92 \pm 9$ & $5 \pm 2$ \\
$5 \mathrm{wt} \% \mathrm{Si}_{3} \mathrm{~N}_{4}: 8$ days & $76 \pm 7$ & $6 \pm 3$ \\
$5 \mathrm{wt} \% \mathrm{Si}_{3} \mathrm{~N}_{4}: 20$ days & $76 \pm 5$ & $7 \pm 2$ \\
\hline
\end{tabular}

\subsection{Discussion}

The behavior at the interphase of nanocomposites depends significantly on the interfacial layer most adjacent to nanoparticles, which in turn is closely related to the surface chemistry of the nanoparticles [13, 14, 22-25]. In the current work, two types of silicon-based nanoparticles with different chemical compounds, i.e., oxide $\left(\mathrm{SiO}_{2}\right)$ and nitride $\left(\mathrm{Si}_{3} \mathrm{~N}_{4}\right)$, were investigated to understand the key phenomena associated with changes in nanoparticle surface chemistries. In Figure 1a, it was illustrated that $\mathrm{SiO}_{2}$ nanoparticles typically contains $\mathrm{Si}-\mathrm{O}-\mathrm{Si}$ bonds. Due to their electronegativity, the oxygen $(\mathrm{O})$ atoms on the $\mathrm{SiO}_{2}$ surface can form stable chemical bonds with almost all elements to give the corresponding oxides. Naturally, the $\mathrm{O}$ atoms have a high tendency to form hydrogen bonding with water molecules. Consequently, $\mathrm{SiO}_{2}$ is prone to water adsorption, where surface hydroxyl $(\mathrm{OH})$ groups tend to be present on the surface of $\mathrm{SiO}_{2}$ when exposed to air or water surroundings. Indeed, available literature $[32,61]$ showed that $\mathrm{SiO}_{2}$ adsorbed significant amount of water even when stored under ambient conditions, suggesting that water can readily be partitioned to polar $\mathrm{SiO}_{2}$ surfaces. 
Meanwhile, $\mathrm{Si}_{3} \mathrm{~N}_{4}$ nanoparticles typically contains $\mathrm{Si}-\mathrm{N}-\mathrm{Si}$ bonds, as illustrated in Figure 1b. According to the Pauline scale [47], the electronegativity of an $\mathrm{N}$ atom is 3.04, less than that of an $\mathrm{O}$ atom (3.44). Therefore, the affinity of the $\mathrm{N}$ atoms on the surface of $\mathrm{Si}_{3} \mathrm{~N}_{4}$ to attract water molecules is lower, albeit that $\mathrm{Si}_{3} \mathrm{~N}_{4}$ exposed to air can form an oxide film on its surface, where the oxidation film can thus react with water $[42,48]$. This was also reported in previous findings $[32,61]$ where, under ambient conditions, $\mathrm{Si}_{3} \mathrm{~N}_{4}$ adsorbed little water compared to $\mathrm{SiO} 2$. Therefore, the water adsorption effects were much less pronounced for $\mathrm{Si}_{3} \mathrm{~N}_{4}$ compared to $\mathrm{SiO}_{2}$. The results from the current water immersion test were, indeed, in line with the above illustrated surface chemistry changes. LDPE is hydrophobic in nature, so it repels rather than absorbs water [49]. Consequently, no appreciable changes in mass were observed for unfilled LDPE. Since unfilled LDPE was not affected by its surrounding water, the breakdown strength of unfilled LDPE remained similar upon water immersion.

Meanwhile, most nanoparticles are hydrophilic in nature. The addition of hydrophilic nanoparticles to hydrophobic LDPE would render the resulting nanocomposite material to become hygroscopic - having tendency to absorb or adsorb water from surroundings. Based on the current experimental work on LDPE with $20 \mathrm{SiO}_{2}$ or $80 \mathrm{SiO}_{2}$, an increase in the materials' mass was recorded upon water immersion. The increase in mass could be attributed to the presence of water within $\mathrm{LDPE} / \mathrm{SiO}_{2}$ interphase, since $\mathrm{OH}$ groups tend to be formed on the surface of $\mathrm{SiO}_{2}$. With increasing water immersion periods, more water molecules could reside within the interphase, and this negatively affected the breakdown strength.

The presence of water within nanocomposites are not unusual and was anticipated by Zou et al. [27] and Fabiani et al. [29] through their proposed water shell models, where layers of water were expected to surround nanoparticles (at the interphase). Rowe [50] suggested the "interphase aging scenario", whereby water that diffused into composites would reach the particle/polymer 
interphase where it accumulated, thus forming a network of semi inter-connected water pathway at the interphase. Percolation of water through the interphase would then occur, and an electrical path would appear through the sample, initiating conduction current and a runaway mechanism that would lead to electrical breakdown. Indeed, Hosier et al. [51, 52] reported increased electrical conductivity, dielectric loss and permittivity, thus reduced breakdown strength, as a consequence of increased water absorption in polyethylene/silica nanocomposites. A progressive reduction in breakdown strength with increasing moisture content was also observed by many other researchers [53-55], in agreement with the current findings.

The use of nanometer-size fillers commonly leads to the presence of more extensive interfacial areas [12], hence higher amounts of absorbed water. While using $\mathrm{SiO}_{2}$ with a larger manufacturer-quoted diameter, i.e., $80 \mathrm{SiO}_{2}$, was expected to reduce the water absorption effect due to its smaller overall interfacial areas compared to $20 \mathrm{SiO}_{2}$, this was not apparent in the current work. This imply two possibilities. First, the water absorption characteristics were similar in LDPE with $20 \mathrm{SiO}_{2}$ and $80 \mathrm{SiO}_{2}$, indicating that they absorbed water in a similar way. Second, the water absorption characteristics were different in $\mathrm{LDPE}$ with $20 \mathrm{SiO}_{2}$ and $80 \mathrm{SiO}_{2}$, but these characteristic change was difficult to be measured directly from the current experiment. The latter is thought to be more relevant, since the breakdown strength of $\mathrm{LDPE}$ with $80 \mathrm{SiO}_{2}$ was higher than that of $\mathrm{LDPE}$ with $20 \mathrm{SiO}_{2}$ counterparts, thus indicating less water molecules within the LDPE with $80 \mathrm{SiO}_{2}$.

Significantly, the addition of $\mathrm{Si}_{3} \mathrm{~N}_{4}$ to LDPE resulted in much less water absorption when compared to the addition of $20 \mathrm{SiO}_{2}$ or $80 \mathrm{SiO}_{2}$ to LDPE. In this regard, different surface chemistries governing of $\mathrm{Si}_{3} \mathrm{~N}_{4}$ and $\mathrm{SiO}_{2}$ is important. Since the affinity of $\mathrm{N}$ atoms on the surface of $\mathrm{Si}_{3} \mathrm{~N}_{4}$ to attract water molecules is lower than $\mathrm{O}$ atoms on the surface of $\mathrm{SiO}_{2}$, water is less attractive to the surface of $\mathrm{Si}_{3} \mathrm{~N}_{4}$. Nevertheless, the presence of the interphase region in LDPE with $\mathrm{Si}_{3} \mathrm{~N}_{4}$ could still serve as a preferable site for the aggregation of water molecules. Since this region would 
nevertheless contain water upon water immersion, the breakdown strength of LDPE with $\mathrm{Si}_{3} \mathrm{~N}_{4}$ would be negatively affected. It is noteworthy that the breakdown strength of LDPE with $\mathrm{Si}_{3} \mathrm{~N}_{4}$ significantly decreased although very few water was absorbed. This could be a consequence of the formation of a percolating water network that enhanced electrical conductivity in well dispersed $\mathrm{Si}_{3} \mathrm{~N}_{4}$-based nanocomposites; in $\mathrm{SiO}_{2}$-based nanocomposites, a percolating network was not formed due to particle aggregation [32]. Consequently, small changes in water content could manifest themselves as major changes in electrical performance.

The breakdown strength of LDPE reduced with increasing amounts of $\mathrm{SiO}_{2}$ or $\mathrm{Si}_{3} \mathrm{~N}_{4}$ loading levels. This has often been associated with nanoparticles aggregation $[56,57]$. Nevertheless, the current breakdown results indicated that the same sample, when immersed in water, could result in much lower breakdown strength. Therefore, although the aggregation of nanoparticles could negatively affect the breakdown strength of nanocomposites, the presence of water could also be detrimental to the breakdown strength of the materials. Furthermore, an apparent increase in mass could be noticed for LDPE with $10 \mathrm{wt} \%$ of $\mathrm{SiO}_{2}$ than $3 \mathrm{wt} \%$ of $\mathrm{SiO}_{2}$. This could be related to increased interphase volumes (and therefore increased water contents) as a consequence of increased nanoparticles amounts. The breakdown strength of LDPE with higher $\mathrm{SiO}_{2}$ loading levels was consequently further reduced.

In the previous work $[58,59]$, changes in the permittivity values of nanoparticles were demonstrated to affect the electric field distribution within nanocomposites, thus the breakdown performance. Generally, nanoparticles with permittivity values higher than polymers showed distorted electric field intensity within the resulting nanocomposites, and the distortion effect amplifies if the permittivity of nanoparticles further increases. So, the breakdown strength of a material is commonly reported to be inversely proportional to the permittivity of the material [60]. In the current work, however, the permittivity of $\mathrm{Si}_{3} \mathrm{~N}_{4}$ (7.5) was higher than $\mathrm{SiO}_{2}$ (3.9), but adding 
$\mathrm{Si}_{3} \mathrm{~N}_{4}$ to LDPE resulted in higher breakdown strength than adding $\mathrm{SiO}_{2}$ to LDPE even before the water immersion test. The current results are, nevertheless, consistent with the work of Hosier et al. [61] in comparing the breakdown strength of polyethylene containing $\mathrm{Si}_{3} \mathrm{~N}_{4}$ and $\mathrm{SiO}_{2}$. Hosier et al. $[32,61]$ suggested that as-received $\mathrm{Si}_{3} \mathrm{~N}_{4}$ nanoparticles were generally drier than as-received $\mathrm{SiO}_{2}$ nanoparticles under ambient conditions, so the overall permittivity of polyethylene/ $\mathrm{Si}_{3} \mathrm{~N}_{4}$ nanocomposites was lower than polyethylene/SiO 2 nanocomposites. Consequently, the effects of nanofillers' permittivity on the breakdown strength of nanocomposites were overshadowed by the effects of water surrounding the nanofillers. It is therefore important to note that, while addressing permittivity mismatches between the nanoparticles and the polymer is crucial in nanocomposites, efforts to eliminate water on nanoparticles' surface or within the nanocomposite interphase are of equal importance. This is because water could readily be adsorbed onto the surface of nanoparticles, creating a volume of water within the interphase, thus jeopardizing the dielectric properties of nanocomposites.

\subsection{Conclusions}

The current work demonstrated that the addition of oxide- and nitride-based silicon nanoparticles to LDPE could alter the material's water absorption behavior. While LDPE itself is hydrophobic, LDPE when added with $\mathrm{SiO}_{2}$ nanoparticles, became prone to water absorption. In contrast, LDPE with $\mathrm{Si}_{3} \mathrm{~N}_{4}$ nanoparticles attracted much less water. These water absorption behaviors consequently affected the breakdown properties of the materials, where LDPE with $\mathrm{SiO}_{2}$ nanoparticles showed lower breakdown strength than LDPE with $\mathrm{Si}_{3} \mathrm{~N}_{4}$ nanoparticles. The observed changes in the water absorption and breakdown characteristics of the nanocomposites were attributed to the interfacial mechanisms of the nanocomposites, in particular, in relation to surface chemistries of $\mathrm{SiO}_{2}$ and $\mathrm{Si}_{3} \mathrm{~N}_{4}$. Significantly, the results from the breakdown tests showed 
that understanding nanoparticles' surface chemistry and hence the nanocomposite interphase, in relation to its water absorption (or adsorption) behavior is particularly important, since the presence of water in any dielectrics is strongly undesirable.

\section{Acknowledgments}

The authors acknowledge the Ministry of Higher Education, Malaysia and Universiti Teknologi Malaysia for financial sponsorships and the research grants 03G66 and 13H12.

\section{References}

[1] Kozako M, Fuse N, Ohki Y, Okamoto T and Tanaka T. Surface degradation of polyamide nanocomposites caused by partial discharges using IEC (b) electrodes. IEEE Trans Dielectr Electr Insul 2004; 11: 833-839.

[2] Nelson J K and Fothergill J C. Internal charge behaviour of nanocomposites. Nanotechnology 2004; 15: 586-595.

[3] Tanaka T, Montanari G C and Mülhaupt R. Polymer nanocomposites as dielectrics and electrical insulation- perspectives for processing technologies, material characterisation and future applications IEEE Trans Dielectr Electr Insul 2004; 11: 763-784.

[4] Montanari G C, Palmieri F, Testa L, Motori A, Saccani A and Patuelli F. Polarization processes of nanocomposite silicate-EVA and PP materials. IEEJ Trans Fundam Mater 2006; 126: 1090-1096.

[5] Thablet A and Ebnalwaled AA. Improvement of surface energy properties of PVC nanocomposites for enhancing electrical applications. Measurement 2017; 110: 78-83.

[6] Green C D, Vaughan A S, Mitchell G R and Liu T. Structure property relationships in polyethylene/montmorillonite nanodielectrics. IEEE Trans Dielectr Electr Insul 2008; 15: 134-143.

[7] Xu G C, Wang J, Ji X L, Xiong J Y and Li F. Effect of nano-silicon nitride on the mechanical and electric properties of polypropylene nanocomposite. J Compos Mater 2007; 41: 2213-2223. 
[8] Ngagaraju SC, Roy AS and Ramgopal G. Conductivity of surface modified TiO2 dope nanocomposites. Measurement 2015; 60: 214-221.

[9] Roy M, Nelson J K, MacCrone R K, Schadler L S, Reed C W, Keefe R and Zenger W. Polymer nanocomposite dielectrics - the role of the interface. IEEE Trans Dielectr Electr Insul 2005; 12: 629642.

[10] Shah AH and Rizvi TZ. Improvement in electrical and thermal behavior of polystyrene/multiwalled carbon nanotubes nanocomposites. Measurement 2012; 46: 1541-1550.

[11] Virtanen S, Ranta H, Ahonen S, Karttunen M, Pelto J, Kannus K and Pettersson M. Structure and dielectric breakdown strength of nano calcium carbonate/polypropylene composites. J Appl Polym Sci 2014; 131: 39504 (1-8).

[12] Nelson JK. Overview of nanodielectrics: Insulating materials of the future. Proc IEEE Electrical Insulation Conference and Electrical Manufacturing Expo 2007 (Nashville, USA); pp 229-235.

[13] Lewis TJ. Interfaces are the dominant feature of dielectrics at the nanometric level IEEE Trans Dielectr Electr Insul 2004; 11: 739-753.

[14] Tanaka T, Kozako M, Fuse N and Ohki Y. Dielectric nanocomposites with insulating properties. IEEE Trans Dielectr Electr Insul 2005; 12: 669-681.

[15] Raetzke S and Kindersberger J. Role of interphase on the resistance to high-voltage arcing, on tracking and erosion of silicone/SiO 2 nanocomposites. IEEE Trans Dielectr Electr Insul 2010; 17: 607-614.

[16] Racherla V. Colossal dielectric constant polymer nanocomposites: Role of charge injection at matrixfiller interfaces. J Compos Mater 2012; 47: 2353-2360.

[17] Fréchette MF et al. Nanodielectrics: a panacea for solving all electrical insulation problems? Proc IEEE Int Conf on Solid Dielectrics (Postdam, Germany); pp 130-158.

[18] Lau KY, Vaughan AS, Chen G. Nanodielectrics: Opportunities and challenges. IEEE Electr Insul Mag $2015 ; 31: 45-54$.

[19] Raju GG. Chapter 16: Nanodielectrics, in Dielectrics in Electric Fields (2 ${ }^{\text {nd }}$ Ed) 2017; CRC Press, Taylor \& Francis Group. 
[20] Xiang D, Wang L, Tang Y, Harkin-Jones E, Zhao C and Li Y. Processing-property relationships of biaxially stretched binary carbon nanofiller reinforced high density polyethylene nanocomposites. Mater Lett 2017; 209: 551-554.

[21] Xiang D, Wang L, Tang Y, Zhao C Harkin-Jones E and Li Y. Effect of phase transitions on the electrical properties of polymer/carbon nanotube and polymer/graphene nanoplatelet composites with different conductive network structures. Polym Int 2018; 67: 227-235.

[22] Lewis TJ. Nanometric dielectrics. IEEE Trans Dielectr Electr Insul 1994; 1: 812-825.

[23] Lewis TJ. Interfaces: nanometric dielectrics. J Phys D: Appl Phys 2005; 38: 202-212.

[24] Li S, Yin G, Chen G, Li J, Bai S, Zhong L, Zhang Y and Lei Q. Short-term breakdown and long-term failure in nanodielectrics: a review. IEEE Trans Dielectr Electr Insul 2010; 17: 1523-1535.

[25] Singha S and Thomas MJ. Dielectric properties of epoxy nanocomposites. IEEE Trans Dielectr Electr Insul 2008; 15: 12-23.

[26] Zhang C and Stevens GC. The dielectric response of polar and non-polar nanodielectrics. IEEE Trans Dielectr Electr Insul 2008; 15: 606-617.

[27] Zou C, Fothergill JC and Rowe SW. The effect of water absorption on the dielectric properties of epoxy nanocomposites. IEEE Trans Dielectr Electr Insul 2008; 15: 106-117.

[28] Huang X, Liu F and Jiang P. Effect of nanoparticle surface treatment on morphology, electrical, and water treeing behaviour of LLDPE composites IEEE Trans Dielectr Electr Insul 2010; 17: 1697-1704

[29] Fabiani D, Montanari GC and Testa L. Effect of aspect ratio and water contaminant on the electric properties of nanostructured insulating materials. IEEE Trans Dielectr Electr Insul 2010; 17: 221-230.

[30] Lau KY, Vaughan AS, Chen G and Hosier IL. Dielectric response of polyethylene nanocomposites: The effect of surface treatment and water absorption. IEEE Ann Rep Conf Electrical Insulation and Dielectric Phenomena (Montreal, Canada) 2012; pp. 275-278.

[31] Lau KY, Vaughan AS, Chen G, Hosier IL and Holt AF. On the dielectric response of silica-based polyethylene nanocomposites. J Phys D: Appl Phys 2013; 46: 095303 (1-9) 
[32] Hosier IL, Praeger M, Vaughan AS and Swingler SG. The effects of water on the dielectric properties of silicon-based nanocomposites. IEEE Trans Nanotechnology 2017; 16: 169-179.

[33] Kinloch AJ, Little MSG and Watts JF. The role of the interphase in the environmental failure of adhesive joints. Acta Materialia 2000; 48(18-19): 4543-4553.

[34] Gonon P, Pham Hong T, Lesaint O, Bourdelais S and Debruyne H. Influence of high level of water absorption on the resistivity and dielectric permittivity of epoxy composites. Polym Test 2005; 24: 799804.

[35] Kumazawa T, Oishi M and Todoki M. High-humidity deterioration and internal structure change of epoxy resin for electrical insulation. IEEE Trans Dielectr Electr Insul 1994; 1: 133-138.

[36] Maxwell ID and Pethrick RA. Dielectric studies of water in epoxy resins. J Appl Polym Sci 1983; 28: 2363-2397.

[37] Reid JD and Lawrence WH. Dielectric properties of an epoxy resin and its composite I. Moisture effects on dipole relaxation. J Appl Polym Sci 1986; 31: 1771-1784.

[38] Daoud WA, Xin JH and Tao X. Synthesis and characterisation of hydrophobic silica nanocomposites. Appl. Surface Sci 2006; 252: 5368-5371.

[39] Lai S, Huang C, Li S, Chen Y, Hsu H, Yu Y and Hsiou Y. Preparation and properties of melt-mixed metallocene polyethylene/silica nanocomposites. Polym Eng Sci 2011; 51: 434-444.

[40] Wu C and Liao H. In situ polymerisation of silicic acid in polyethylene-octene elastomer: Properties and characterisation of the hybrid nanocomposites. J Polym Sci B 2003; 41: 351-359.

[41] Parvinzadeh M, Moradian S, Rashidi A and Yazdanshenas M. Surface characterisation of polyethylene terephthalate/silica nanocomposites. Appl Surface Sci 2010; 256: 2792-2802.

[42] Pezzotti G. Bioceramics for hip joints: the physical chemistry viewpoint. Materials 2014; 7: 4367-4410.

[43] Bugaev KO, Zelenina AA and Volodin VA. Vibrational spectroscopy of chemical species in silicon and silicon-rich nitride thin films. Int J Spectroscopy 2012; 281851 (1-5). 
[44] Cheng G, Qian J, Tang Z, Ding G and Zhu J. Dispersion stability of $\mathrm{Si}_{3} \mathrm{~N}_{4}$ nano-particles modified by $\gamma$-methacryloxypropyl trimethoxy silane (MAPTMS) inorganic solvent. Ceramics Int 2015; 41: 18791884.

[45] Weibull W. A statistical distribution function of wide applicability. J Appl Mech 1952; 18: 293-297.

[46] Fothergill JC. Estimating the cumulative probability of failure data points to be plotted on Weibull and other probability paper. IEEE Trans Electr Insul 1990; 25: 489-492.

[47] Pauling L. The nature of the chemical bond. IV. The energy of single bonds and the relative electronegativity of atoms. J Am Chem Soc 1932; 54: 3570-3582.

[48] Raider SI, Flitsch R, Aboaf, JA and Pliskin WA. Surface oxidation of $\mathrm{Si}_{3} \mathrm{~N}_{4}$ films. J Electrochem Soc 1976; 123: 560-565.

[49] Steeman PAM, Maurer FHJ and van Es MA. Dielectric monitoring of water absorption in glass-beadfilled high-density polyethylene. Polymer 1991; 32: 523-530.

[50] Rowe SW. Electrical ageing of composites: an industrial perspective. Proc IEEE Int Conf Solid Dielectrics 2007 (Winchester, UK); pp. 401-406.

[51] Hosier IL, Praeger M, Holt AF, Vaughan AS and Swingler SG. Effect of water absorption on dielectric properties of nano-silica/polyethylene composites. IEEE Ann Rep Conf Electrical Insulation and Dielectric Phenomena (Des Moines, USA) 2014; pp. 651-654.

[52] Hosier IL, Praeger M, Holt AF, Vaughan AS and Swingler SG. On the effect of functionalizer chain length and water content in polyethylene/silica nanocomposites: part 1 - dielectric properties and breakdown strength. IEEE Trans Dielectr Electr Insul 2017; 24: 1698-1707.

[53] Ma DL, Siegel RW, Hong JI, Schadler LS, Martensson E and Onneby C. Influence of nanoparticle surfaces on the electrical breakdown strength of nanoparticle-filled low-density polyethylene", J Mat Res 2004; 19: 857-863.

[54] Hui L, Schadler LS and Nelson JK. The influence of moisture on the electrical properties of crosslinked polyethylene/silica nanocomposites. IEEE Trans Dielectr Electr Insul 2013; 20; 641-653. 
[55] Jaeverbeg N, Venkatesulu B, Edin H and Hillborg H. Prebreakdown current and DC breakdown strength of alumina-filled poly(ethyleneco-butyl acrylate) nanocomposites: part I - breakdown strength. IEEE Trans Dielectr Electr Insul 2014; 21: 2127-2134.

[56] Huang X, Ma Z, Wang Y, Jiang P, Yin Y and Li Z. Polyethylene/aluminium nanocomposites: improvement of dielectric strength by nanoparticle surface modification. J Appl Polym Sci 2009; 113: $3577-3584$.

[57] Vaughan A S, Swingler S G and Zhang Y. Polyethylene nanodielectrics: the influence of nanoclays on structure formation and dielectric breakdown. IEEJ Trans Fund Mater 2006; 126: 1057-1063.

[58] Lau KY, Muhamad NA, Bashir N, Arief YZ, Piah MAMP, Vaughan AS and Chen G. Modeling of polymer nanocomposites: Permittivity vs. electric field intensity. Proc IEEE Int Conf Power and Energy 2014 (Kuching, Malaysia); pp 140-145.

[59] Lau KY, Piah MAMP and Ching KY. Correlating the breakdown strength with electric field analysis for polyethylene/silica nanocomposites. J Electrostatics 2017; 86: 1-11.

[60] Neusel C and Schneider GA. Dependence of the breakdown strength on thickness and permittivity. Proc IEEE Int Conf Solid Dielectrics 2013 (Bologna, Italy); pp. 31-35.

[61] Hosier IL, Praeger M, Vaughan AS and Swingler SG. The effects of hydration on the DC breakdown strength of polyethylene composites employing oxide and nitride fillers. IEEE Trans Dielectr Electr Insul 2017; 24: 3073-3082. 